\title{
Thermal and spectral analysis of copolymers with sulphur groups
}

\author{
Karolina Fila $^{1}$ Marta Grochowicz ${ }^{1}$ (i) $\cdot$ Beata Podkościelna ${ }^{1}$
}

Received: 7 August 2017 / Accepted: 10 November 2017/Published online: 17 November 2017

(C) The Author(s) 2017. This article is an open access publication

\begin{abstract}
The paper presents the synthesis, structure and polymerization of S-phenyl 2-methylprop-2-enethioate (PSM). This compound was prepared in the reaction of thiophenol with methacryloyl chloride. The obtained PSM was purified on the chromatographic column. Chemical structure of the monomer was confirmed by spectroscopic methods (ATR-FTIR, GC-MS, ${ }^{1} \mathrm{H}$ and ${ }^{13} \mathrm{C}$ NMR). Next bulk polymerization of PSM with styrene ( $\mathrm{St}$ ) or methyl methacrylate (MMA) was performed. In this way, linear copolymers were obtained. The number and mass average molar mass of the obtained copolymers were determined by gel permeation chromatography (GPC). Additionally, crosslinked copolymers of the commercial monomer $S, S^{\prime}$ thiodi-4,1-phenylene bis(thiomethacrylate) (DMSPS) under the same conditions were synthesized. The influence of thiol monomers on the physico-chemical properties of the obtained copolymers was determined. Thermal properties of the synthesized materials were investigated by means of DSC and TG/DTG.
\end{abstract}

Keywords Synthesis - Thiophenol - Bulk polymerization · Average molar mass $\cdot$ DSC $\cdot$ TG/DTG

Marta Grochowicz

mgrochowicz@umcs.pl

Beata Podkościelna

beatapod@umcs.pl

1 Department of Polymer Chemistry, Maria Curie-Skłodowska University, Lublin, Poland

\section{Introduction}

Thiols are the sulphur analogues of alcohols, but hydrogen atom in the thiol group is more acidic than that in hydroxyl group. These organic compounds commonly occur in nature. Thiols and sulphides perform important biological functions, especially in life processes. There are also known other applications of thiols, e.g., as chain transfer agents in the synthesis of polymers used for optical devices [1-4].

In the last few years there has been a growing interest in the methods of controlled radical polymerization that allows the synthesis of polymers with a defined molecular mass and a low dispersion of these mass. The molecular mass control of polymers is an important issue because final physical and mechanical properties of the polymer depend on the length of its chain. In order to control the length of the polymer chain, so-called chain transfer agents are used in polymerization process. Thiols are well-defined chain transfer agents in the free radical polymerization for such ordinary monomers as styrene or methyl methacrylate. Thiols play a significant role among the chain transfer agents because of their efficiency in obtaining polymers of the desired molecular mass. Two important parameters that determine such use of thiols are weakness of the S-H bond and high reactivity of the thiol radicals [4-6]. The weakness of the $\mathrm{S}-\mathrm{H}$ bond can be explained by the high reactivity of these compounds towards chain-carrying macroradicals, leading to high chain transfer constants, irrespectively of the used monomer. In turn, high reactivity of the thiol radicals is characterized by almost ideal chain transfer behaviour of thiols, with a large decrease in the polymer molecular mass without a substantial change in the polymerization rate [7-10]. 
Henriquez et al. [11] studied the chain transfer properties of thiophenol and several water-soluble aliphatic thiols for the polymerization of acrylamide and 1-vinyl-2pyrrolidone in the aqueous solution at $25{ }^{\circ} \mathrm{C}$. They showed that the addition of millimolar concentrations of thiols for the polymerization of acrylamide reduced notably the molecular mass of the polymer, without change in the polymerization rate. Measurements at different $\mathrm{pH}$ values indicated that the reactive factor is the protonated $-\mathrm{SH}$ group. Chain transfer constants, determined from the Mayo plots, are only slightly dependent on the thiol structure. Aliphatic thiols and thiophenol react at similar rates. The reaction rates of these sulphur compounds with the electrophilic 2,2-diphenyl-1-picrylhydrazyl radical showed higher selectivity and are not related with the chain transfer constants measured for the acrylamide macroradicals. These results are explained in terms of different factors that control the reactivity of thiols with macroradicals [12, 13].

In this paper, synthesis and copolymerization of the new methacrylic derivative of thiophenol-S-phenyl 2-methylprop-2-enethioate (PSM) - are discussed. The chemical structure of PSM was confirmed by the ATR-FTIR, GCMS, ${ }^{1} \mathrm{H}$ and ${ }^{13} \mathrm{C}$ NMR spectroscopy. Next bulk copolymerization of PSM with styrene (St) and methyl methacrylate (MMA) was performed. For comparison, the copolymerization of the commercial monomer $S, S^{\prime}$-thiodi4,1-phenylene bis(thiomethacrylate) with St and MMA was also carried out. Methyl methacrylate and styrene were used as main comonomers because (especially MMA) they are widely used in POF (polymer optical fibre technology) [13-16]. Molecular mass control is a crucial feature in the POFs technology since it affects significantly the quality of the obtained materials, especially their optical properties. So far thiols with at least one free - SH group are usually used as chain transfer agents in the POFs technology $[17,18]$. The proposed PSM monomer is a methacrylic derivative of thiophenol with the vinyl group capable of polymerization with MMA and St. This compound was added as a comonomer, and its effect on the molecular mass of the resulting copolymers was determined with the use of GPC method. Moreover, the effects of different chemical structure of monomers [two- (PSM) or fourfunctional (DMSPS), aromatic (St) or aliphatic (MMA)] on the thermal properties of the resulting copolymers were studied by means of DSC and TG/DTG methods.

\section{Experimental}

\section{Materials}

Thiophenol, methylene chloride, methyl methacrylate, triethylamine and $S, S^{\prime}$-thiodi-4,1-phenylene bis(thiomethacrylate) were obtained from Sigma-Aldrich. Methacryloyl chloride was from Fluka AG (Buchs, Switzerland). $\alpha, \alpha^{\prime}$-Azoiso-bisbutyronitrile (AIBN) was purchased from Merck (Darmstadt, Germany). Styrene and magnesium sulphate were obtained from POCh (Gliwice, Poland). All chemicals were used as received.

\section{Synthesis of methacrylic thiophenol}

In a 500- $\mathrm{cm}^{3}$ round-bottomed flask equipped with a mechanical stirrer, a thermometer and a dropper, thiophenol $(22 \mathrm{~mL})$ and methylene chloride $(225 \mathrm{~mL})$ were placed with $33.4 \mathrm{~mL}$ of triethylamine in an ice bath and stirred for $0.5 \mathrm{~h}$. Next methacryloyl chloride $(23 \mathrm{~mL})$ was added dropwise for $1 \mathrm{~h}$ in the temperature range of $0-5^{\circ} \mathrm{C}$. Subsequently, the flask contents were stirred for $3 \mathrm{~h}$ at $5{ }^{\circ} \mathrm{C}$ and for $1 \mathrm{~h}$ at room temperature. After the reaction, the resulting precipitate was filtered off, and magnesium sulphate $(25 \mathrm{~g})$ was added to the filtrate. The obtained methacrylic derivative of thiophenol-S-phenyl 2-methylprop-2-enethioate, in the form of colourless liquid, was extracted with methylene chloride and purified on the chromatographic column (chloroform/hexane 80:20) [19]. Figure 1 shows the scheme of the synthesis.

\section{Copolymerization of PSM and DMSPS with styrene (St) and methyl methacrylate (MMA)}

The chemical structures of all monomers used in polymerization are presented in Fig. 2. Bulk polymerization of methacrylic derivative of thiophenol (PSM) and $S, S^{\prime}$ thiodi-4,1-phenylene bis(thiomethacrylate) (DMSPS) with the commercial monomers styrene and methyl methacrylate was carried out. Copolymerization reactions were performed in the glass form, with different mass ratios of monomers $(1: 10,1: 20)$ as shown in Table $1 . \alpha, \alpha^{\prime}$-Azoisobis-butyronitrile was used as an initiator $(1 \%, \mathrm{w} / \mathrm{w})$. The reactions were carried out in the water bath at $60{ }^{\circ} \mathrm{C}$ for $2 \mathrm{~h}$ and $90{ }^{\circ} \mathrm{C}$ for $12 \mathrm{~h}$. Homopolymers of St and MMA were obtained under the same conditions.

\section{Characterization}

The ATR-FTIR spectra were obtained on a Bruker FTIR spectrophotometer TENSOR 27.

The ${ }^{1} \mathrm{H}$ and ${ }^{13} \mathrm{C}$ NMR spectra were recorded on a Bruker Avance 300 MSL instrument (Bruker, Germany) operating at $300 \mathrm{MHz}$ for ${ }^{1} \mathrm{H}$ and $75 \mathrm{MHz}$ for ${ }^{13} \mathrm{C}$ resonance frequency. Chemical shifts were referenced to deuterated chloroform $\left(\mathrm{CDCl}_{3}\right)$ which served as an internal standard.

Cross-polarization magic angle spinning (CP-MAS ${ }^{13} \mathrm{C}$ NMR) measurements were completed on the same 
Fig. 1 Scheme of synthesis of methacrylic derivative of thiophenol<smiles>Sc1ccccc1</smiles>

$+$<smiles>C=C(C)C(=O)Sc1ccccc1</smiles>

PSM<smiles>C=Cc1ccc([Se])cc1</smiles><smiles>C=C(C)C(=O)Sc1ccc(Sc2ccc(SC(=O)C(=C)C)cc2)cc1</smiles>

Fig. 2 Chemical structure of monomers used in copolymerization

spectrometer at resonance frequency of $75.5 \mathrm{MHz}$. The number of scans was 2048, and the spin rate was $8000 \mathrm{~Hz}$.

GC-MS was made on a Thermo-Finnigan DSQ spectrometer (Finnigan, USA) hyphenated with a gas chromatograph Trace GC-Ultra equipped with a fused-silica RTX-5 capillary column $(20 \mathrm{~m} \times 0.18 \mathrm{~mm}$ I.D., film thickness $0.20 \mu \mathrm{m})$. The conditions were as follows: injector PTV-split 1:20, program temperature $35-320{ }^{\circ} \mathrm{C}$ with the rate $20^{\circ} \mathrm{C} \mathrm{min}^{-1}$; MS electron ionization at $70 \mathrm{eV}$, temperature of ion volume $220^{\circ} \mathrm{C}$.

Differential scanning calorimetry (DSC) curves were obtained with the use of a DSC Netzsch 204 calorimeter (Netzsch, Germany). All DSC measurements were taken in the aluminium pans with a pierced lid of the sample mass of $\sim 5-10 \mathrm{mg}$ under nitrogen atmosphere $\left(30 \mathrm{~mL} \mathrm{~min}{ }^{-1}\right)$. As the reference, an empty aluminium crucible was used. Dynamic scans were made at a heating rate of $10 \mathrm{~K} \mathrm{~min}^{-1}$ in the temperature range $20-500{ }^{\circ} \mathrm{C}$. The decomposition temperatures ( $\left.T_{\text {onset }}, T_{\text {offset }}\right)$, final decomposition temperature $\left(T_{\mathrm{d}}\right)$, glass transition temperature $\left(T_{\mathrm{g}}\right)$ and enthalpy of decomposition $\left(\Delta H_{\mathrm{d}}\right)$ were determined.

The TG/DTG curves were obtained with the use of a thermal analyser STA 449 F1 Jupiter (Netzsch, Germany). All measurements were taken in the $\mathrm{Al}_{2} \mathrm{O}_{3}$ crucible with the sample mass $\sim 7 \mathrm{mg}$ under helium atmosphere $\left(20 \mathrm{~mL} \mathrm{~min}{ }^{-1}\right)$. Dynamic scans were made at the heating rate of $10 \mathrm{~K} \mathrm{~min}^{-1}$ in the temperature range $30-800{ }^{\circ} \mathrm{C}$. The initial decomposition temperature (IDT), loss mass temperatures $\left(T_{1}\right)$, peak maximum decomposition temperature $\left(T_{\max }\right)$ and final decomposition temperature $\left(T_{\mathrm{f}}\right)$ were determined.

The number $\left(M_{\mathrm{n}}\right)$, mass $\left(M_{\mathrm{w}}\right)$ average molar mass $\left(\mathrm{g} \mathrm{mol}^{-1}\right)$ and the molar mass dispersity $\left(M_{\mathrm{w}} / M_{\mathrm{n}}\right)$ of the obtained copolymers were determined by the gel permeation chromatography (GPC) performed on a Viscotek GPCmax (Viscotek, USA) equipped with the triple detector array TDA 305. The eluent was tetrahydrofuran (THF), the flow rate was $1 \mathrm{~mL} \mathrm{~min}^{-1}$, the operation temperature was set to be $35^{\circ} \mathrm{C}$, and the molar mass was calibrated with the polystyrene standards.

\section{Results and discussion}

\section{The ATR-FTIR analysis for thiophenol and its methacrylic derivative (PSM)}

The methacrylic derivative of thiophenol was prepared by the reaction of thiophenol with methacryloyl chloride. The ATR-FTIR spectra of thiophenol and its methacrylic

Table 1 The amount of monomers used for copolymerization

\begin{tabular}{llllll}
\hline Monomer & Comonomer & $\begin{array}{l}\text { Copolymerization } \\
\text { rates }(\mathrm{w} / \mathrm{w})\end{array}$ & $\begin{array}{l}\text { Amount of obtained } \\
\text { monomer/g }\end{array}$ & $\begin{array}{l}\text { Amount of } \\
\text { comonomer/g }\end{array}$ & $\begin{array}{l}\text { Initiator (AIBN) } \\
(\mathrm{w} / \mathrm{w}) / \%\end{array}$ \\
\hline PSM & St & $1: 10$ & 0.2 & 2 & 0.044 \\
& & $1: 20$ & 0.1 & 2 & 0.042 \\
& MMA & $1: 10$ & 0.2 & 2 & 0.044 \\
DMSPS & $1: 20$ & $1: 10$ & 0.1 & 2 & 0.042 \\
& St & $1: 20$ & 0.2 & 2 & 0.044 \\
& & $1: 10$ & 0.1 & 2 & 0.042 \\
& MMA & $1: 20$ & 0.2 & 2 & 0.044 \\
\hline
\end{tabular}




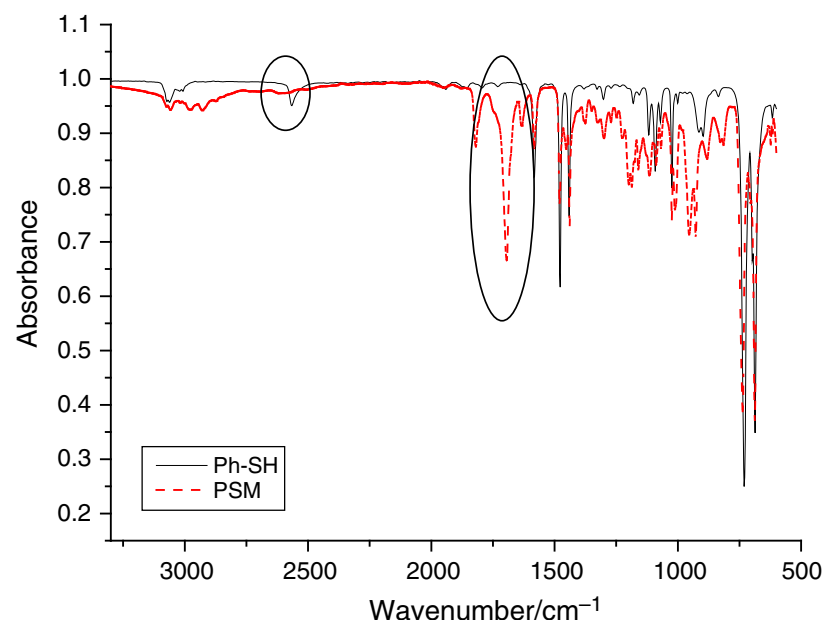

Fig. 3 ATR/FTIR spectra of thiophenol (Ph-SH) and methacrylic derivative of thiophenol (PSM)

derivative (PSM) are presented in Fig. 3. The spectra show the absorption bands derived from stretching vibrations of the aromatic groups $\mathrm{C}_{\mathrm{Ar}}-\mathrm{H}$ at the wavelengths of 3067 and $3058 \mathrm{~cm}^{-1}$, respectively. Another absorption bands present in the spectra of thiophenol and its derivative are the deformation vibrations of $\mathrm{Ar}-\mathrm{H}$ at the wavelength of 730 and $690 \mathrm{~cm}^{-1}$.

The spectrum of the thiophenol shows also the characteristic absorption band derived from the stretching vibrations of thiol group at the wavelength of $2565 \mathrm{~cm}^{-1}$ which disappears after the reaction with methacryloyl chloride. This indicates the correct course of the modification reaction. In the spectrum of the methacrylic derivative of thiophenol, $\mathrm{C}-\mathrm{H}$ stretching vibrations of methyl groups are observed at 2929 and $2977 \mathrm{~cm}^{-1}$, the stretching vibrations of the carbonyl group at $1694 \mathrm{~cm}^{-1}$ and the deformation vibrations of $-\mathrm{CH}=\mathrm{CH}_{2}$ group at $950 \mathrm{~cm}^{-1}$.

\section{The NMR analysis for methacrylic derivative of thiophenol (PSM)}

The chemical structure of methacrylic derivative of thiophenol (PSM) was confirmed by ${ }^{1} \mathrm{H}$ and ${ }^{13} \mathrm{C}$ NMR analysis. The detailed information about signals is presented below.

${ }^{1} \mathrm{H}$ NMR $\left(300 \mathrm{MHz}, \mathrm{CDCl}_{3}, \delta, \mathrm{ppm}\right): 2.05(\mathrm{~m}, 3 \mathrm{H})$; $5.75(\mathrm{~m}, 1 \mathrm{H}) ; 6.35(\mathrm{~m}, 1 \mathrm{H}) ; 7.40(\mathrm{~m}, 5 \mathrm{H})$.

${ }^{13} \mathrm{C}$ NMR $\left(75 \mathrm{MHz}, \mathrm{CDCl}_{3}, \delta, \mathrm{ppm}\right): 18.02\left(-\mathrm{CH}_{3}\right)$; $127.61\left(=\mathrm{CH}_{2}\right) ; 129.63$ (2ArC)- 131.01 (2ArC); 135.02 $(=\mathrm{C}) ; 135.70(\mathrm{ArC}) ; 200.26(\mathrm{C}=\mathrm{O})$.

\section{GC-MS analysis}

Chemical structure of PSM was also confirmed by the GCMS analysis. As its spectrum was not available in the library, identification was achieved analysing molecular

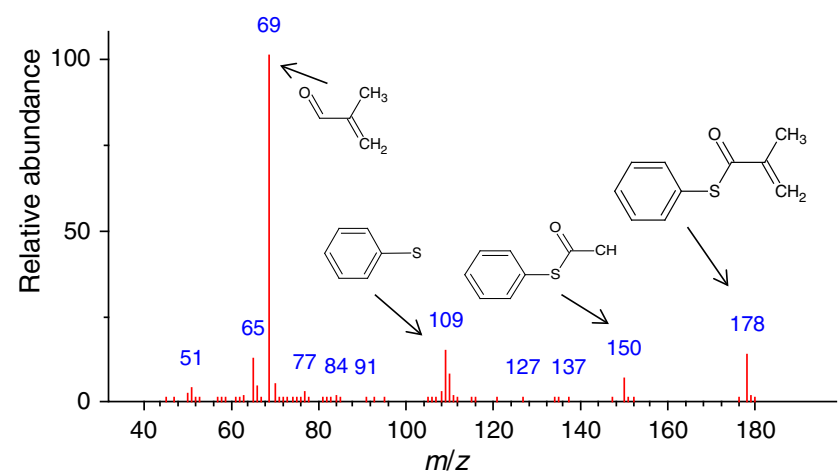

Fig. 4 MS spectrum of the PSM

and fragmentary ions. In the spectrum presented in Fig. 4, molecular ion corresponding to the calculated molecular weight of S-phenyl 2-methylprop-2-enethioate $(\mathrm{m} /$ $z=178$ ) is visible. Besides, a number of fragmentary ions are also noticeable, the most important ones are identified, and their meaning is presented in spectrum.

\section{The analysis of the ATR-FTIR spectra of obtained copolymers}

The ATR-FTIR spectra of the homopolymer of styrene (Sthomo) and copolymer of styrene with the methacrylic derivative of thiophenol (St-PSM) or $S, S^{\prime}$-thiodi-4,1-phenylene bis(thiomethacrylate) (St-DMSPS) are presented in Fig. 5. Generally, similar absorption bands are present in both spectra. However, for the copolymers (St-PSM and StDMSPS) the appearance of the characteristic vibrations of the carbonyl group (1699 and $1735 \mathrm{~cm}^{-1}$ ) was observed. The presence of carbonyl groups (derived from methacrylate unit) indicates the incorporation of the thiol monomer into the structure of the resulting copolymers. This confirms the planned course of copolymerization processes.

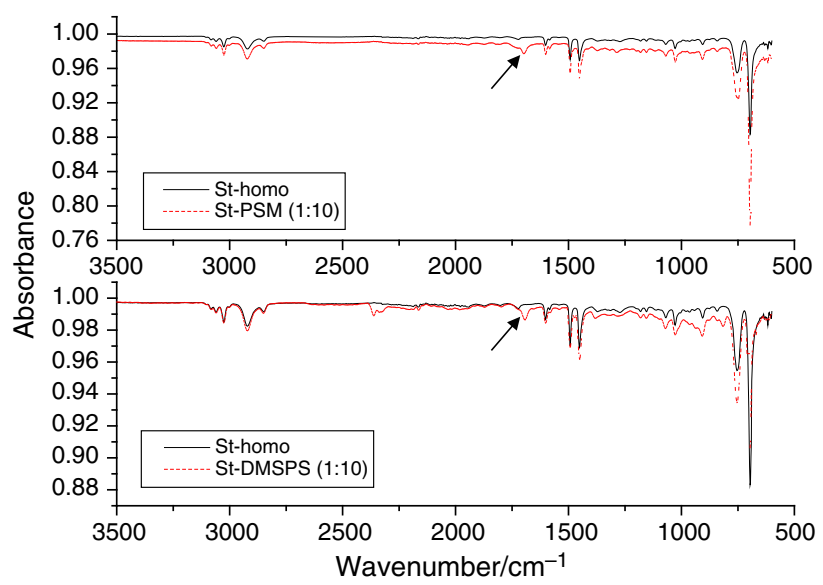

Fig. 5 The ATR/FTIR spectra of homopolymer of styrene (St-homo) and its copolymers: St-PSM and St-DMSPS in ratio 1:10 
Table 2 ATR-FTIR data of the homopolymer of styrene and its copolymers

\begin{tabular}{|c|c|c|c|c|c|c|}
\hline \multirow[t]{2}{*}{ Polymer } & \multicolumn{6}{|l|}{ Wavenumber $/ \mathrm{cm}^{-1}$} \\
\hline & $\begin{array}{l}\mathrm{C}_{\mathrm{Ar}}-\mathrm{H} \text { stretching } \\
\text { vibrations }\end{array}$ & $\begin{array}{l}-\mathrm{CH}_{2} \text { stretching } \\
\text { vibrations }\end{array}$ & $\begin{array}{l}\mathrm{C}=\mathrm{O} \text { stretching } \\
\text { vibrations }\end{array}$ & $\begin{array}{l}\mathrm{C}=\mathrm{C} \\
\text { aromatic }\end{array}$ & $\begin{array}{l}\text { - } \mathrm{CH} \text { bending } \\
\text { vibrations }\end{array}$ & $\begin{array}{l}\mathrm{C}_{\mathrm{Ar}}-\mathrm{H} \text { bending } \\
\text { vibrations }\end{array}$ \\
\hline \multirow[t]{2}{*}{ St-homo } & 3026 & 2921 & - & 1600 & 1450 & 696 \\
\hline & & & & & 1492 & 752 \\
\hline \multirow[t]{2}{*}{ St-PSM (1:10) } & 3026 & 2923 & 1699 & 1601 & 1450 & 697 \\
\hline & & & & & 1492 & 752 \\
\hline \multirow[t]{2}{*}{ St-DMSPS (1:10) } & 3025 & 2921 & 1735 & 1597 & 1448 & 696 \\
\hline & & & & & 1490 & 754 \\
\hline
\end{tabular}

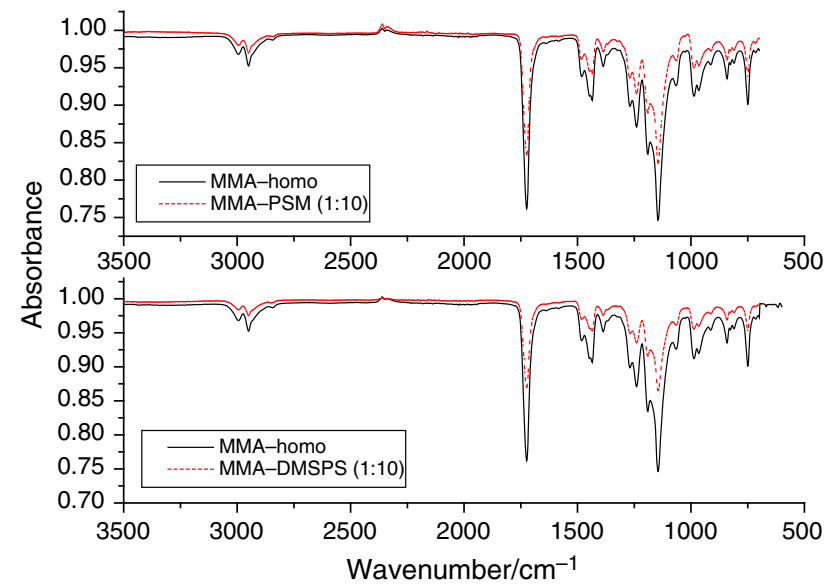

Fig. 6 The ATR/FTIR spectra of homopolymer of methyl methacrylate (MMA-homo) and its copolymers: MMA-PSM and MMADMSPS in ratio $1: 10$

Table 2 shows the most characteristic absorption bands for the obtained copolymers with styrene.

In Fig. 6, the ATR-FTIR spectra of the homopolymer of methyl methacrylate (MMA-homo) and copolymers of MMA-PSM and MMA-DMSPS are presented. Due to the small contribution of sulphur monomer and the presence of similar groups, only slight changes in spectra are visible. Table 3 shows the most characteristic absorption bands for the obtained copolymers with methyl methacrylate.

\section{${ }^{13}$ C CP-MAS NMR}

For the complete spectroscopic investigation of copolymers, an analysis ${ }^{13} \mathrm{C}$ CP-MAS NMR was carried out. The spectra of styrene copolymers with PSM and DMSPS are presented in Fig. 7a, b. Spectra have a very similar course because the main component of studied copolymers is styrene; only the signal at 234-235 ppm derives from the carbonyl groups present in PSM and DMSPS comonomers (Table 4).

\section{Thermal properties of copolymers}

Thermal properties of the obtained copolymers were studied by means of DSC analysis. The DSC curves of the styrene and methyl methacrylate homopolymers and their copolymers St-PSM, St-DMSPS, MMA-PSM and MMADMSPS are presented in Figs. 8, 9, 10 and 11, respectively. In addition, the measurement results of the DSC are given in Tables 5 and 6.

The DSC analysis showed similarity in the thermal behaviour of all prepared copolymers. They have a characteristic, well-shaped calorimetric profile revealing the presence of a single endothermic peak. The obtained data indicate that the synthesized copolymers are characterized by high thermal resistance. In the case of the St-PSM and St-DMSPS copolymers, the endothermic peak at

Table 3 ATR-FTIR data of the homopolymer of methyl methacrylate and its copolymers

\begin{tabular}{|c|c|c|c|c|c|}
\hline \multirow[t]{2}{*}{ Polymer } & \multicolumn{5}{|c|}{ Wavenumber $/ \mathrm{cm}^{-1}$} \\
\hline & $\begin{array}{l}-\mathrm{CH}_{3} \text { stretching } \\
\text { vibrations }\end{array}$ & $\begin{array}{l}-\mathrm{CH}_{2} \text { stretching } \\
\text { vibrations }\end{array}$ & $\begin{array}{l}\mathrm{C}=\mathrm{O} \text { stretching } \\
\text { vibrations }\end{array}$ & $\begin{array}{l}\text { - } \mathrm{CH} \text { bending } \\
\text { vibrations }\end{array}$ & $\begin{array}{l}\mathrm{C}-\mathrm{O}-\mathrm{C} \\
\text { vibrations }\end{array}$ \\
\hline MMA-homo & 2995 & 2940 & 1726 & 1446 & $\begin{array}{l}1138 \\
1242\end{array}$ \\
\hline MMA-PSM (1:10) & 2993 & 2935 & 1726 & $\begin{array}{l}1429 \\
1493\end{array}$ & $\begin{array}{l}1191 \\
1233\end{array}$ \\
\hline MMA-DMSPS (1:10) & 2997 & 2947 & 1726 & 1443 & $\begin{array}{l}1146 \\
1242\end{array}$ \\
\hline
\end{tabular}



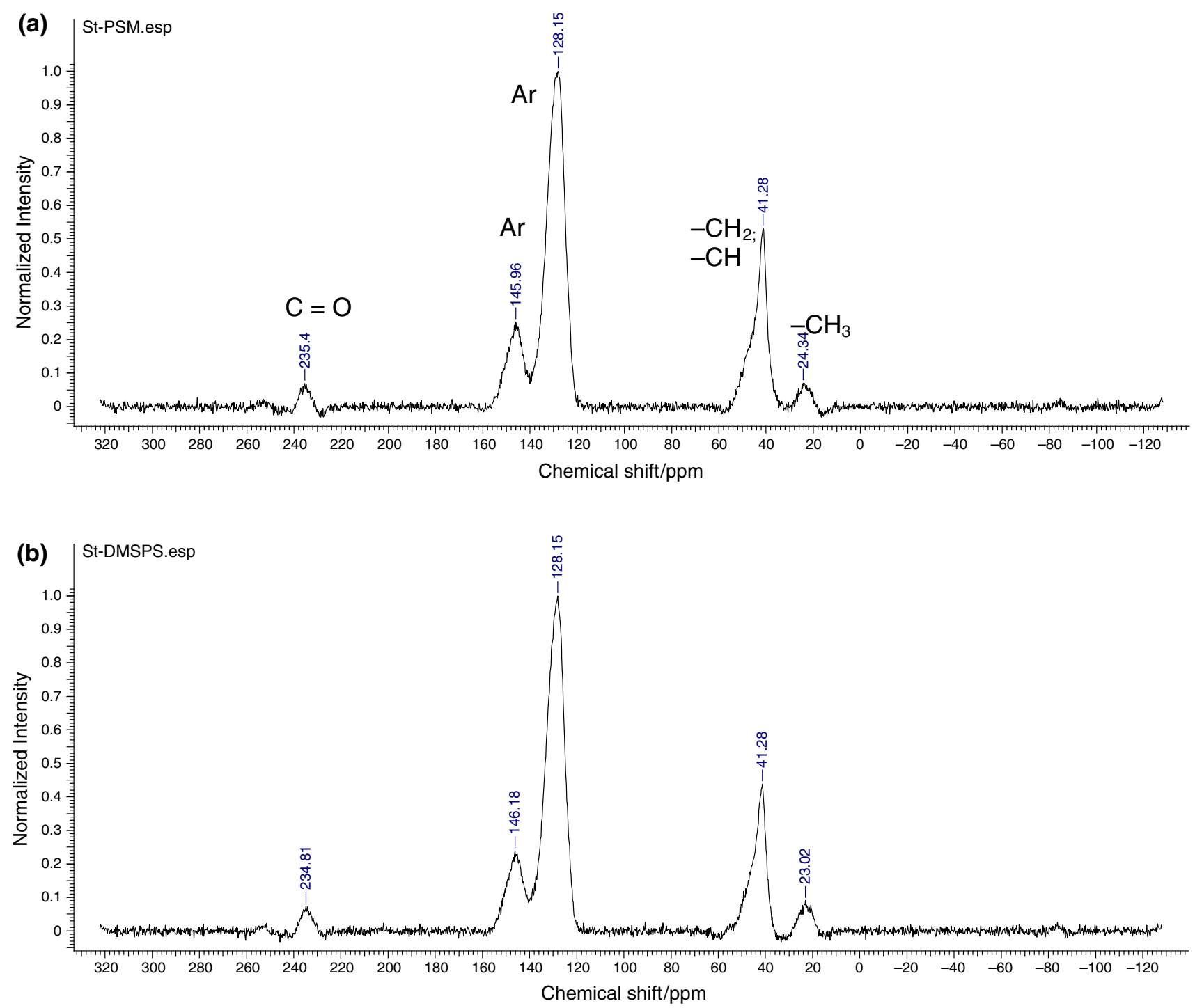

Fig. 7 a, $\mathbf{b}^{13} \mathrm{C}$ CP-MAS NMR spectra of styrene copolymers with PSM and DMSPS

Table $4{ }^{13} \mathrm{C}$ CP-MAS NMR signals of styrene copolymers

\begin{tabular}{llll}
\hline Sample & \multicolumn{2}{l}{ Signals/ppm } & \\
\cline { 2 - 4 } & Alkyl C & Aromatic C & Carbonyl C \\
\hline St-PSM & 24.34 & 128.15 & 235.47 \\
& 41.28 & 145.96 & \\
St-DMSPS & 23.02 & 128.15 & 234.81 \\
& 41.28 & 146.18 & \\
\hline
\end{tabular}

$392-417{ }^{\circ} \mathrm{C}$ is associated with their total thermal degradation. For the MMA-PSM and MMA-DMSPS copolymers, decomposition occurs in the temperature range of 358-389 ${ }^{\circ} \mathrm{C}$. The enthalpy of decomposition $\left(\Delta H_{d}\right)$ values ranges from 597.8 to $884.1 \mathrm{~J} \mathrm{~g}^{-1}$ depending on the amount

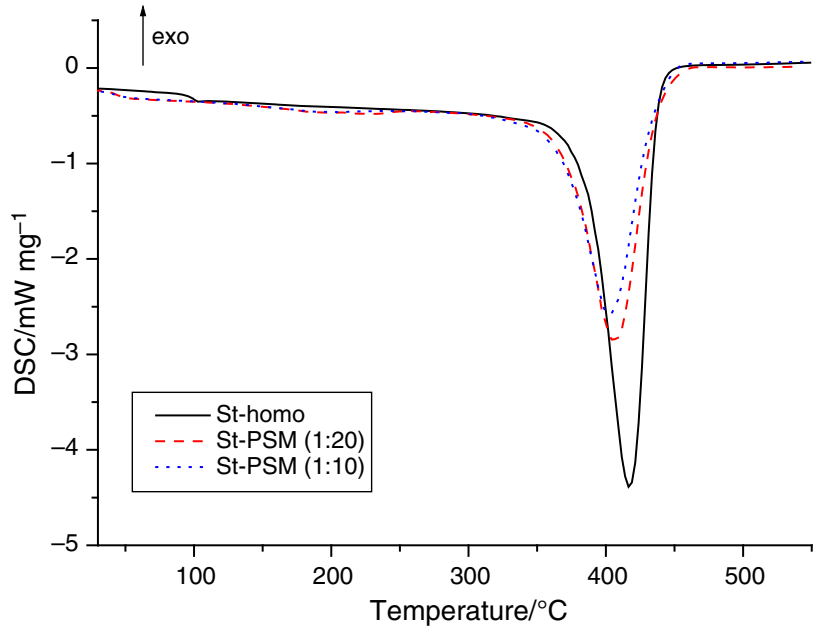

Fig. 8 DSC curves of St-homo and copolymers of St-PSM in ratio 1:10 and $1: 20$ 


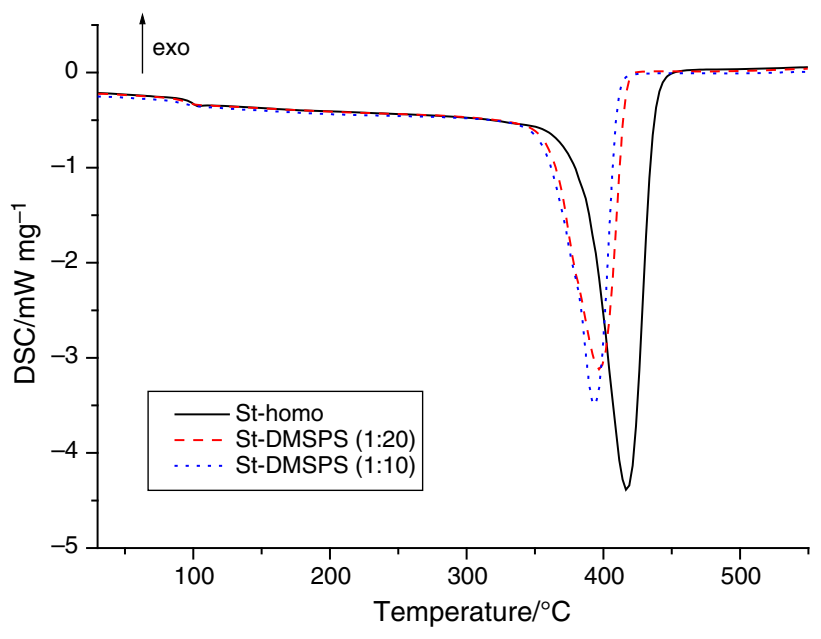

Fig. 9 DSC curves of St-homo and copolymers of St-DMSPS in ratio $1: 10$ and $1: 20$

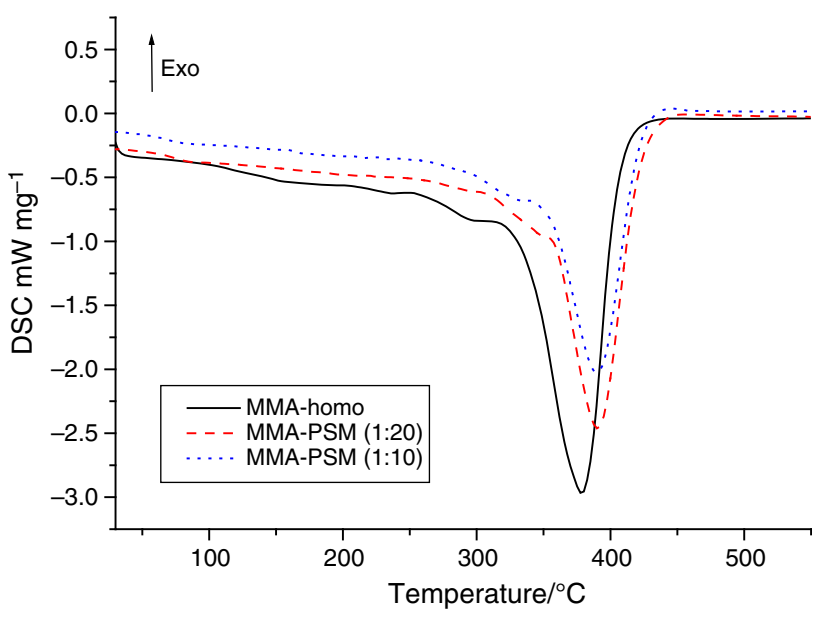

Fig. 10 DSC curves of MMA- homo and copolymers of MMA-PSM in ratio $1: 10$ and $1: 20$

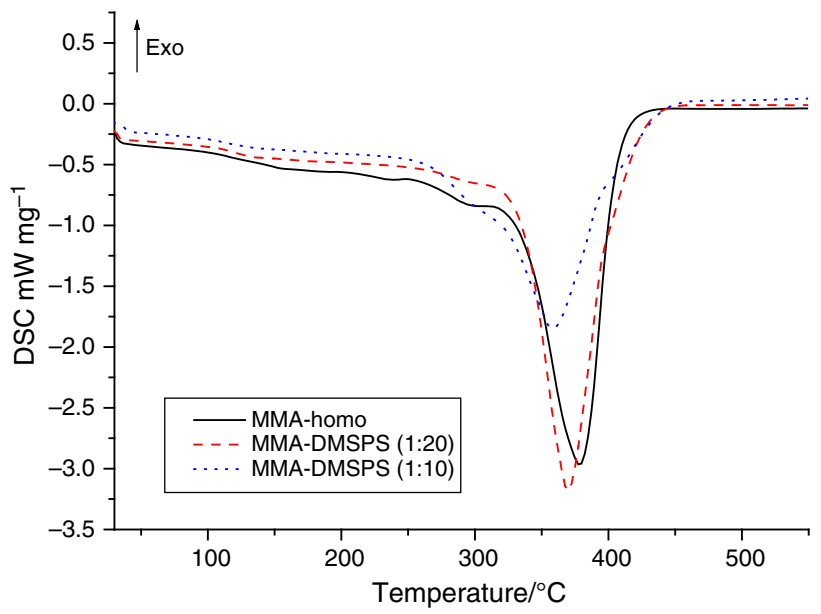

Fig. 11 DSC curves of MMA-homo and copolymers of MMADMSPS in ratio $1: 10$ and 1:20
Table 5 DSC analyses of the homopolymer of styrene and its copolymers

\begin{tabular}{llllll}
\hline Copolymer & $T_{\mathrm{g}} /{ }^{\circ} \mathrm{C}$ & $T_{\text {onset }} /{ }^{\circ} \mathrm{C}$ & $T_{\text {offset }} /{ }^{\circ} \mathrm{C}$ & $T_{\mathrm{d}} /{ }^{\circ} \mathrm{C}$ & $\Delta H_{\mathrm{d}} / \mathrm{J} \mathrm{g}^{-1}$ \\
\hline St-homo & 99.8 & 345 & 460 & 417 & 875.5 \\
St-PSM (1:10) & 92.9 & 310 & 470 & 408 & 758.7 \\
St-PSM (1:20) & 87.9 & 330 & 470 & 410 & 743.6 \\
St-DMSPS (1:10) & 96.4 & 330 & 422 & 392 & 597.8 \\
St-DMSPS (1:20) & 97.3 & 335 & 426 & 398 & 627.4 \\
\hline
\end{tabular}

Table 6 DSC analyses of the homopolymer of methyl methacrylate and its copolymers

\begin{tabular}{lrllll}
\hline Copolymer & $T_{\mathrm{g}} /{ }^{\circ} \mathrm{C}$ & $T_{\text {onset }} /{ }^{\circ} \mathrm{C}$ & $T_{\text {offset }} /{ }^{\circ} \mathrm{C}$ & $T_{\mathrm{d}} /{ }^{\circ} \mathrm{C}$ & $\Delta H_{\mathrm{d}} / \mathrm{J} \mathrm{g}$ \\
\hline MMA-homo & 120.3 & 275 & 438 & 376 & 884.1 \\
MMA-PSM (1:10) & 75.1 & 267 & 448 & 389 & 749.5 \\
MMA-PSM (1:20) & 72.9 & 272 & 445 & 389 & 666.8 \\
MMA- & 113.1 & 245 & 454 & 358 & 760.5 \\
$\quad$ DMSPS (1:10) & & & & & \\
MMA- & 121.4 & 306 & 451 & 371 & 769.7 \\
$\quad$ DMSPS (1:20) & & & & & \\
\hline
\end{tabular}

Table 7 Results of TG/DTG analysis of the St-homo and its copolymers: St-PSM and St-DMSPS in mass 1:10

\begin{tabular}{llllll}
\hline Polymer & $I D T /{ }^{\circ} \mathrm{C}$ & $T_{\max 1} /{ }^{\circ} \mathrm{C}$ & $T_{\max 2} /{ }^{\circ} \mathrm{C}$ & $T_{\max 3} /{ }^{\circ} \mathrm{C}$ & $T_{\mathrm{f}} /{ }^{\circ} \mathrm{C}$ \\
\hline St-homo & 311 & - & 396 & - & 420 \\
St-PSM (1:10) & 219 & 236 & 406 & - & 440 \\
St-DMSPS (1:10) & 314 & - & 382 & 600 & 620 \\
\hline
\end{tabular}

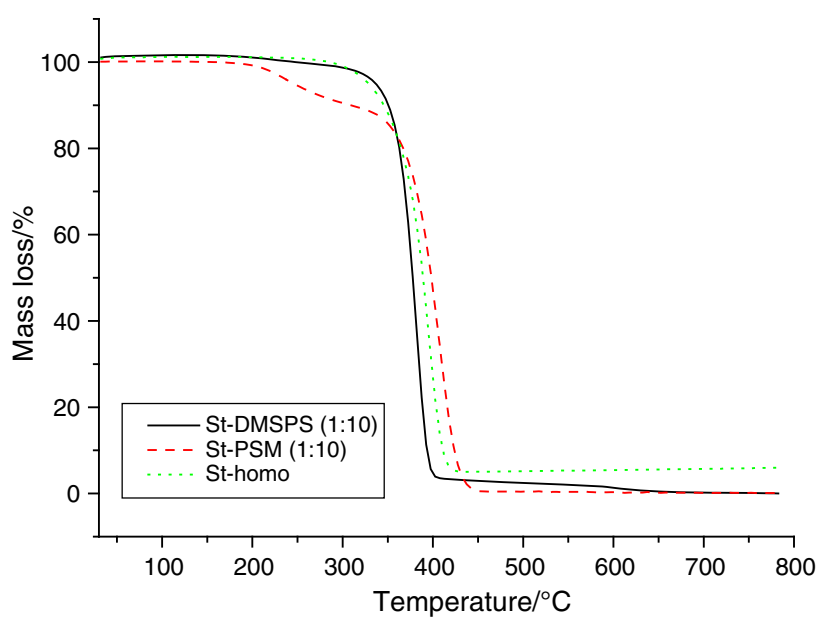

Fig. 12 TG curves of St-homo and its copolymers St-DMSPS and StPSM in mass $1: 10$ 


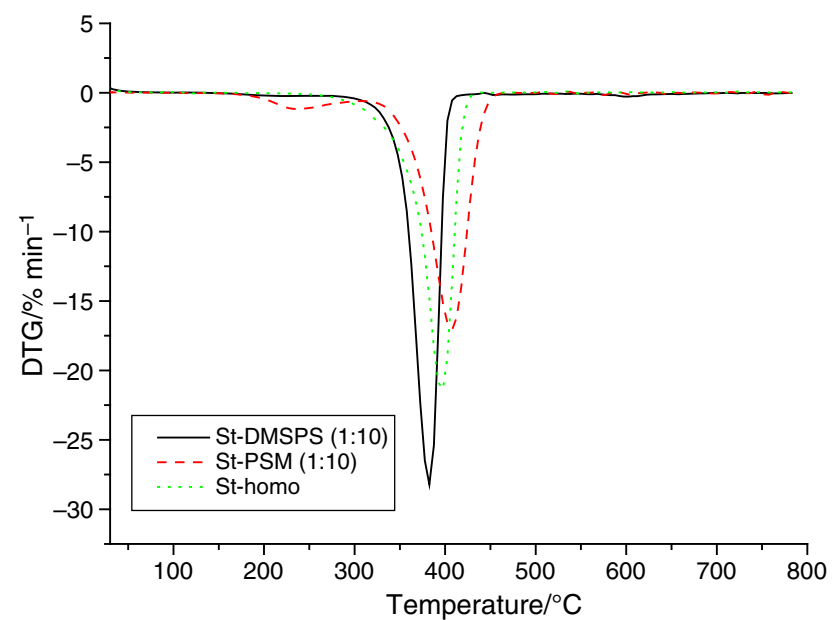

Fig. 13 DTG curves of St-homo and its copolymers St-DMSPS and St-PSM in mass 1:10

of the monomers used during copolymerization. The higher the degree of crosslinking, the higher the thermal stability and consequently a lower value of $\Delta H_{\mathrm{d}}$. The enthalpy of decomposition for copolymers of St and MMA decreases with increasing mass fraction of the PSM and DMSPS. The glass transition temperature $\left(T_{\mathrm{g}}\right)$ for the tested copolymers was also determined, and it was found for all polymers. The highest value of the $T_{\mathrm{g}}\left(121.4{ }^{\circ} \mathrm{C}\right)$ possesses MMADMSPS (1:20) copolymer, while the lowest MMA-PSM $(1: 20)$ copolymer $\left(72.9^{\circ} \mathrm{C}\right)$. Copolymers of styrene have a similar $T_{\mathrm{g}}$ values ranging from 87.9 to $99.8{ }^{\circ} \mathrm{C}$. With the increase in the amount of PSM or DMSPS in the structure of the copolymers, the faster decrease in glass transition temperature takes place [20-22].

Thermal stability and degradation behaviour of the styrene copolymers were studied by means of thermogravimetry. The TG/DTG results of thermal decomposition process are presented in Table 7 and Figs. 12, 13. For the St-homo and St-DMSPS copolymers, the TG curves have almost the same course, and the initial decomposition temperature (IDT, corresponding to the temperature of $2 \%$ of mass loss) is about 311 and $314{ }^{\circ} \mathrm{C}$, respectively. In the case of St-PSM, the initial decomposition temperature is about $219^{\circ} \mathrm{C}$. The final decomposition temperatures $\left(T_{\mathrm{f}}\right)$ for the St-homo and St-PSM copolymer are about $420{ }^{\circ} \mathrm{C}$, whereas for the St-DMSPS copolymer $T_{\mathrm{f}}$ is $620^{\circ} \mathrm{C}$.

The DTG curve for the St-homo polymer contains one separate degradation step. The maximum decomposition peak is observed in the range $300-410{ }^{\circ} \mathrm{C}$ with the maximum of the mass loss $\left(T_{\max }\right)$ at $396{ }^{\circ} \mathrm{C}$ and is related to its total degradation according to the chain scission and free radical diffusion mechanism [18]. In the case of St-PSM and St-DMSPS, the DTG curves contain two separate maxima related to the degradation stages. In the DTG
Table 8 GPC data of the styrene and methyl methacrylate homopolymers and their copolymers with PSM

\begin{tabular}{lrrl}
\hline Polymer & \multicolumn{2}{c}{ Average molecular mass } & Dispersity $M_{\mathrm{w}} / M_{\mathrm{n}}$ \\
\cline { 2 - 3 } & \multicolumn{1}{c}{$M_{\mathrm{n}} / \mathrm{Da}$} & \multicolumn{1}{c}{$M_{\mathrm{w}} / \mathrm{Da}$} & \\
\hline St-homo & 47,600 & 102,900 & 2.16 \\
St-PSM (1:20) & 20,900 & 55,700 & 2.66 \\
St-PSM (1:10) & 22,500 & 52,500 & 2.33 \\
MMA-homo & $1,974,000$ & $2,939,000$ & 1.48 \\
MMA-PSM (1:20) & 118,900 & 288,900 & 2.43 \\
MMA-PSM (1:10) & 56,300 & 193,500 & 3.44 \\
\hline
\end{tabular}

curve of St-PSM, the first decomposition peak between 180 and $300{ }^{\circ} \mathrm{C}$ with the maximum of mass loss $\left(T_{\max 1}\right)$ at $236{ }^{\circ} \mathrm{C}$ and the mass loss of about $10 \%$ is connected with the decomposition of network fragments derived from PSM monomer. The second decomposition stage takes place between 315 and $425^{\circ} \mathrm{C}$ with the maximum of mass loss $\left(T_{\max 2}\right)$ at $406{ }^{\circ} \mathrm{C}$. The DTG curve of St-DMSPS is of different character which is associated with the structure of this copolymer. Because the DMSPS monomer possesses two methacrylate groups, the copolymer obtained with styrene has a crosslinked network. Thus at $382{ }^{\circ} \mathrm{C}\left(T_{\max 2}\right)$ the main decomposition of the linear fragments of the copolymer takes place, whereas at $600{ }^{\circ} \mathrm{C}$ the degradation of the residual of crosslinked part of copolymer is observed.

Analysing the obtained data, one can conclude that the highest thermal resistance was found in the case of the StPSM copolymer (about $10{ }^{\circ} \mathrm{C}$ ), but the earlier start of the decomposition of these copolymers is observed. These materials are stable up to $220{ }^{\circ} \mathrm{C}$. Generally, one can conclude that the copolymers of styrene have a higher thermal stability than the methyl methacrylate copolymers.

\section{Molecular mass}

The average molecular mass $\left(M_{\mathrm{n}}, M_{\mathrm{w}}\right)$ was determined for the copolymers of St-PSM and MMA-PSM by the gel permeation chromatography. The results of GPC analysis are shown in Table 8. As follows from this table, the addition of methacrylic derivative of thiophenol (PSM) affects the molecular mass of the resulting polymers. The PSM additive reduces the average molecular mass of the obtained St-PSM and MMA-PSM copolymers. The largest decrease in the molecular mass is observed for the copolymer MMA-PSM (1:10), while the smallest is for the copolymers of St-PSM. The $M_{\mathrm{w}} / M_{\mathrm{n}}$ relationship indicative the molar mass dispersity for the obtained polymers ranges from 1.48 to 3.43 , and it was at a relatively low level for the polymers obtained in an alloy. 


\section{Conclusions}

The reaction of thiophenol with methacryloyl chloride resulted in a new sulphur monomer-S-phenyl 2-methylprop-2-enethioate (PSM). This compound was obtained in the form of colourless liquid. A detailed spectroscopic analysis (ATR/FTIR, GC-MS, ${ }^{1} \mathrm{H}$ and ${ }^{13} \mathrm{C}$ NMR) of the resulting compound confirmed its chemical structure. The use of PSM compound as a comonomer in the copolymerization reaction with methyl methacrylate and styrene allowed the synthesis of a new group of polymers. DSC and TG/DTG measurements indicated that the obtained copolymers possess high thermal resistance; they are stable up to $220^{\circ} \mathrm{C}$. The thermal stability of the studied copolymers decreased with the increasing amount of PSM. The results of DSC analysis showed an endothermic effect in the range of $358-417^{\circ} \mathrm{C}$ due to the total decomposition of PSM and DMSPS copolymers with methyl methacrylate and styrene. The glass transition temperature of styrene copolymers is about $90{ }^{\circ} \mathrm{C}$, whereas for MMA-DMSPS copolymers $T_{\mathrm{g}}$ is about $115{ }^{\circ} \mathrm{C}$ and about $85{ }^{\circ} \mathrm{C}$ for MMAPSM copolymers. GPC analysis showed that PSM comonomer influenced significantly the molecular mass of StPSM and MMA-PSM copolymers. The average molecular mass $\left(M_{\mathrm{n}}, M_{\mathrm{w}}\right)$ of the obtained copolymers decreased with the increasing amount of PSM comonomer. Taking into account the chemical structure, thermal stability and molecular mass of synthesized PSM copolymers with St and MMA, and from the other hand the trends in POFs technology, it can be supposed that presented in this study PSM monomer can be used as a special additive for polymers used in optical fibres drawing.

Open Access This article is distributed under the terms of the Creative Commons Attribution 4.0 International License (http://crea tivecommons.org/licenses/by/4.0/), which permits unrestricted use, distribution, and reproduction in any medium, provided you give appropriate credit to the original author(s) and the source, provide a link to the Creative Commons license, and indicate if changes were made.

\section{References}

1. Karasu F, Arsu N, Yagci Y. 2-Mercapto thioxanthone as a chain transfer agent in free-radical polymerization: a versatile route to incorporate thioxanthone moieties into polymer chain-ends. J Appl Polym Sci. 2007;103:3766-70.

2. Furuncuoglu T, Ugur I, Degirmenci I, Aviyente V. Role of chain transfer agents in free radical polymerization kinetics. Macromolecules. 2010;43:1823-35.

3. Saikia M, Borphukan S, Baruah U, Shashi PJ, Baruah DS. Poly(ethylene-co-BMA) via dual concurrent ATRP-RAFT and its thermokinetic study. J Therm Anal Calorim. 2017; https://doi. org/10.1007/s10973-017-6536-5.
4. Valdebenito A, Encinas MV. Thiophenols as chain transfer agents in the polymerization of vinyl monomers. Polymer. 2005;46:10658-62.

5. Valdebenito A, Encinas MV. Chain transfer agents in vinyl polymerizations photoinduced by bimolecular photoinitiators. J Photochem Photobiol A. 2008;194:206-11.

6. Lee TY, Roper TM, Jonsson ES, Guymon CA, Hoyle CE. Thiolene photopolymerization kinetics of vinyl acrylate/multifunctional thiol mixtures. Macromolecules. 2004;37:3606-13.

7. Cokbaglan L, Arsu N, Yagci Y, Jockusch S, Turro NJ. 2-Mercaptothioxanthone as a novel photoinitiator for free radical polymerization. Macromolecules. 2003;36:2649-53.

8. Krongauz VV, Chawla CP. Revisiting aromatic thiols effects on radical photopolymerization. Polymer. 2003;44:3871-6.

9. Ito O, Matsuda M. Evaluation of addition rates of thiyl radicals to vinyl monomers by flash photolysis. Polar effect in addition reactions of substituted benzenethiyl radicals. J Am Chem Soc. 1981;103:5871-4.

10. Yang G, Kristufek SL, Link LA, Wooley KL, Robertson ML. Synthesis and physical properties of thiol-ene networks utilizing plant-derived phenolic acids. Macromolecules. 2015;48:8418-27.

11. Henriquez C, Bueno C, Lissi EA, Encinas MV. Thiols as chain transfer agents in free radical polymerization in aqueous solution. Polymer. 2003;44:5559-61.

12. Pogocki D, Schöneich C. Thiyl radicals abstract hydrogen atoms from carbohydrates: reactivity and selectivity. Free Radic Biol Med. 2001;31:98-107.

13. Demirci G, Podkoscielna B, Bartnicki A, Mergo P, Gil M, Cetinkaya O, Gawdzik B. Copolymerization and thermal study of the new methacrylate derivative of 2,4,6-trichlorophenol. J Therm Anal Calorim. 2017;127:2263-71.

14. Yoo HY, Bruckenstein S. A novel quartz crystal microbalance gas sensor based on porous film coatings. A high sensitivity porous poly(methyl methacrylate) water vapor sensor. Anal Chim Acta. 2013;785:98-103.

15. Zubia J, Arrue J. Plastic optical fibers: an introduction to their technological processes and applications. J Opt Fiber Technol. 2001;7:101-40.

16. Sharafudeen KN, Adithya A, Vijayakumar S, Sudheesh P, Kalluraya $\mathrm{B}$, Chandrasekharan K. Multiphoton absorption process and self-focusing effect in coumarin derivative doped PMMA films by z-scan and optical limiting studies. Curr Appl Phys. 2011;11:1089-93.

17. Koike K, Suzuki A, Makino K, Koike Y. Effects of para-fluorine substituent of polystyrene on gradient-index fiber-optic properties. Opt Mater. 2015;39:143-7.

18. Mansour ShA. Study of thermal stabilization for polystyrene/carbon nanocomposites via TG/DSC techniques. J Therm Anal Calorim. 2013;112:579-83.

19. Grochowicz M, Gawdzik B. Preparation and characterization of porous crosslinked microspheres of new aromatic methacrylates. J Porous Mater. 2013;20:339-49.

20. Podkościelna B, Lipke A, Majdan M, Gawdzik B, Bartnicki A. Thermal and photoluminescence analysis of a methacrylic diester derivative of naphthalene-2,7-diol. J Therm Anal Calorim. 2016;126:161-70.

21. Podkościelna B. Synthesis, spectroscopic and thermal characterization of the new photoluminescent monomer 2,7-di(methacryloyloxy)naphthalene and its copolymerization with selected vinyl monomers. J Therm Anal Calorim. 2016;123:273-82.

22. Podkościelna B, Sobiesiak M. Characteristics of thermal behavior of photoluminescent copolymers studied by the TG/DTG/FTIR coupled method. J Therm Anal Calorim. 2017;127:625-31. 